\title{
Radioiodination and biological evaluation of valsartan as a tracer for cardiovascular disorder detection
}

\author{
A. M. Amin ${ }^{1 *}$, A. Abd El-bary ${ }^{2}$, A. Abd El-Mohty ${ }^{3}$, Shokry M. Saad ${ }^{4}$, D. M. El-Sharawy ${ }^{5}$ \\ ${ }^{1}$ Labelled Compound Department, Hot Lab Center, Atomic Energy Authority, Cairo, Egypt; \\ *Corresponding Author: ab amin@hotmail.com \\ ${ }^{2}$ Pharmaceutics and Industrial Pharmacy Department, Faculty of Pharmacy, Cairo University, Cairo, Egypt \\ ${ }^{3}$ Radioactive Isotopes and Generators Department, Atomic Energy Authority, Cairo, Egypt \\ ${ }^{4}$ Nuclear Research Center, Atomic Energy Authority, Cairo, Egypt \\ ${ }^{5}$ Cyclotron Project, Nuclear Research Centre Atomic Energy Authority, Cairo, Egypt
}

Received 25 August 2012; revised 26 September 2012; accepted 9 October 2012

Copyright (C) 2013 A. M. Amin et al. This is an open access article distributed under the Creative Commons Attribution License, which permits unrestricted use, distribution, and reproduction in any medium, provided the original work is properly cited.

\begin{abstract}
A procedure for radioiodination of valsartan with iodine-125 is carried out via an electrophilic substitution of hydrogen atom with the iodonium cation $I^{+}$. All reaction parameters were studied to optimize the labeling conditions of valsartan and to obtain a maximum radiochemical yield (RCY) of the ${ }^{125} \mathrm{I}-$ Valsartan $\left[{ }^{125} \mathrm{I}-\mathrm{Val}\right]$. By using $3.7 \mathrm{MBq}$ of $\mathrm{Na}^{125} \mathrm{l}, 50 \mu \mathrm{g}$ of valsartan $(0.2 \mathrm{mM})$ as substrate, $25 \mu \mathrm{g}$ of lodogen $(0.15 \mathrm{mM})$ as oxidizing agent in ethanol at room temperature for $30 \mathrm{~min}$, the radiochemical yield of ${ }^{125} \mathrm{I}-\mathrm{Val}$ was $98.6 \%$ The radiochemical yield was determined by electrophoresis using cellulose acetate moistened with $0.02 \mathrm{M}$ phosphate buffer pH 7. The labeled compound was separated and purified by means of high-pressure liquid chromatography (HPLC). The biological distribution in normal mice indicates the suitability of radioiodinated valsartan to image any cardiovascular disorders.
\end{abstract}

Keywords: Valsartan; Radioiodination;

Cardiovascular Disorder Imaging

\section{INTRODUCTION}

Myocardial assessment continues to be an issue in patients with coronary artery disease and left ventricular dysfunction. Nuclear imaging has long played an important role in this field. In particular, Positron emission tomography (PET) imaging using ${ }^{18} \mathrm{~F}$-fluorodeoxyglucose is regarded as the metabolic gold standard of tissue viability [1,2], which has been supported by a wide clinical experience. Viability assessment using single photon emission computed tomography (SPECT) techniques has gained more wide-spread clinical acceptance than PET, because it is more widely available at lower cost. Moreover, technical advances in SPECT technology such as gated-SPECT further improve the diagnostic accuracy of the test. Further efforts are necessary to improve the diagnostic performance of nuclear imaging as reliable viability test [3].

Advances in imaging methodology aim at more rapid, more accurate acquisition and hybrid systems additionally, the advent of various molecular-targeted probes is expected to result in novel clinical applications of nuclear cardiology in the future. Several radiopharmaceuticals have been introduced for the scintigraphic visualization of myocardium and cardiovascular disorders. So Valsartan was chosen as a compound for radio-iodination with the radioisotope iodine-125.

Valsartan (Angiotan) is an angiotensin II receptor antagonist (more commonly called an "ARB", or angiotensin receptor blocker), with particularly high affinity for the type I (AT1) angiotensin receptor. By blocking the action of angiotensin the peripheral blood vessels are allowed to widen, which means that there is more space and less resistance in these blood vessels. This is the main mechanism by which the pressure in the blood vessels is lowered [4,5]. Blocking the actions of angiotensin II also increases the amount of fluid removed from the blood by the kidneys. This decreases the amount of fluid in the blood vessels, which also lessens the resistance and pressure in the blood vessels. The combined effect of these changes is to lower the blood pressure, hence valsartan is used to treat high blood pressure [6,7]. The reduced pressure within the blood vessels also means 
that the heart doesn't have to work as hard to pump the blood around the body. Studying of valsartan Pharmacokinetics, disposition and biotransformation was done using $\left[{ }^{14} \mathrm{C}\right]$-radiolabeled valsartan in healthy male volunteers after a single oral dose [8].

The aim of this study is to investigate all factors affecting the labeling process and optimize the conditions required to get a labeled compound with high radiochemical yield and purity. Also, the biodistribution and the efficiency of labeled valsartan in heart and blood vessels will be experimentally evaluated in normal animals. During this study, ${ }^{125}$ I was used in the labeling process due to its availability, suitable energy and half-life for research.

The suggested structure of ${ }^{125} \mathrm{I}-\mathrm{Val}$ was formed via an electrophilic substitution reaction in the presence of iodogen as oxidizing agent as shown in Figure 1.

\section{EXPERIMENTAL}

\subsection{Materials and Methods}

All chemicals used in the present work were of analytical grade. Valsartan, was obtained from Global Naby Pharmaceutical Company, Egypt and was used without any purification. Absolute ethanol was used as a solvent. Double distilled water was used for all experiments. Chloramine-T [N-chloro-P-toluene sulfonamide salt $(\mathrm{CAT})]$ from Aldrich and iodogen (1,3,4,6-tetrachloro$3 \alpha, 6 \alpha$-diphenyl glycoluril) from Pierce Chemical Company. Thin layer chromatography (TLC) aluminum sheets $(20 \times 25 \mathrm{~cm})$ SG-60 $\mathrm{F}_{254}$ (Merck). Na ${ }^{125}$ I (185 $\mathrm{MBq} / 5 \mu \mathrm{L})$ in diluted $\mathrm{NaOH}, \mathrm{pH} 7-11$ was purchased from institute of isotopes, Budapest, Hungary.

\subsection{Equipment}

Radioactivity was measured by means of a gamma counter (Nucleous Model 2010) connected with a well type $\mathrm{NaI}(\mathrm{Tl})$ crystal. High Performance Liquid Chromatography (HPLC) [Sykam Model], S 2100 Solvent delivery system, S 5111 injector valve bracket, S 3240 UV/ VIS spectrophotometric detector and Lichrosorb analytical column C-18 (250 mm $\times 4-6 \mathrm{~mm}, 5 \mu \mathrm{m})$. Electrophoresis was performed with an EC-3000 P-series programmable device (EC Apparatus Corporation) and chamber supply units using cellulose acetate strips.

\subsection{Animals}

Swiss Albino mice weighing 30 - $35 \mathrm{~g}$ were purchased from the agriculture research center, Cairo, Egypt. The animals were kept at constant environmental and nutriational conditions throughout the experimental period and kept at room temperature $\left(22^{\circ} \mathrm{C} \pm 2^{\circ} \mathrm{C}\right)$ with a $12 \mathrm{~h}$ on/off light schedule. The food and water were standard.

\subsection{Labeling of Valsartan with $\mathrm{Na}^{125}$ I Using lodogen as Oxidizing Agent}

An appropriate volume of iodogen solution added to<smiles>CCCCC(=O)N(Cc1ccc(-c2cc([Al])ccc2-c2nnn[nH]2)cc1)[C@@H](C(=O)O)C(C)C</smiles>

Figure 1. The suggested structure of ${ }^{125} \mathrm{I}-\mathrm{Val}$. 
clean glass culture tubes and dried under nitrogen atmosphere. Iodogen was deposited on the wall of the glass tubes as a thin film. The tubes were then closed and stored at $4^{\circ} \mathrm{C}$ till use. Iodination reactions were directly carried out in these tubes. A suitable concentration of valsartan was placed. For labeling, $5 \mu \mathrm{l}$ of $\mathrm{Na}^{125} \mathrm{I}$ (3.7 $\mathrm{MBq}$ ) was added, and then, the reaction mixture was kept at different temperature for interval times. The reaction was stopped simply by removing the aqueous phase and also quenched by the addition of sodium metabisulphite to assure complete cessation of the oxidative process [9].

\subsection{Radiochemical Analysis}

The radiochemical yield of ${ }^{125} \mathrm{I}-\mathrm{Val}$ was determined by TLC \& electrophoresis and the radiochemical purity was determined using HPLC.

\subsection{Thin Layer Chromatography (TLC)}

The radiochemical yield $\%$ of ${ }^{125} \mathrm{I}-\mathrm{V}$ al was determined using aluminum-backed silica gel 60 . A volume of $5 \mu \mathrm{l}$ reaction mixture was placed on the start line, then chromatographed using methylene chloride: ethyl acetate (2:1 $\mathrm{v} / \mathrm{v}$ ) [10] as a developing system. The strips were removed, dried and cut into $1 \mathrm{~cm}$ segments and assayed for radioactivity using SR.7 gamma counter. The relative first $R_{f}$ for free ${ }^{125} \mathrm{I}=0.0-0.1$ and $\mathrm{R}_{\mathrm{f}}$ for labeled compounds $=0.9$. The radiochemical yield was calculated as the percent ratio of activity of labeled compound relative to the total activity on the TLC-strip.

\subsection{Electrophoresis}

Electrophoresis was done using cellulose acetate strips. These strips were moistened with $0.02 \mathrm{M}$ phosphate buffer $\mathrm{pH} 7$ and then were placed in the chamber. Samples of $5 \mu \mathrm{L}$ were applied at a distance of $12 \mathrm{~cm}$ from cathode. Standing time and applied voltage were continued for $90 \mathrm{~min}$, developed strips were removed, dried and cut into $1 \mathrm{~cm}$ segments. They were counted using a well-type $\mathrm{NaI}(\mathrm{Tl})$ detector connected with a single-channel counter. An analysis of samples from the reaction mixture resulted in two peaks as shown in Figure 2, one corresponding to the free iodide which moved towards the anode with $11 \mathrm{~cm}$ distance while ${ }^{125} \mathrm{I}-\mathrm{Val}$ remained at the point of spotting, depending on their charge and ionic mobility [11]. It gave RCY equal to $98.6 \%$.

\subsection{HPLC}

The detection of ${ }^{125} \mathrm{I}-\mathrm{Val}$ with high performance liquid chromatography was done using 0.2 M Sodium dihydrogen phosphate: Acetonitril with ratio (58:42), and the flow rate was $1 \mathrm{ml} / \mathrm{min}$. As shown in Figure 8, two peaks were obtained. The first peak was at 2 minutes, whereas the second peak was at 7 minutes retention time. The first peak corresponds to free iodide, whereas the second peak corresponds to the ${ }^{125} \mathrm{I}-\mathrm{Val}$ as shown in Figure 3.

\subsection{Biodistribution Studies}

Albino mice were used for quantitative biodistribution studies. $200 \mu \mathrm{l}(3.5 \mathrm{MBq})$ of ${ }^{125} \mathrm{I}-\mathrm{Val}$ was injected intravenously (i.v.) in the mice tail vein. Groups of three mice were used for each experiment. The mice were sacrificed by cervical dislocation at $0.5,1$ and $3 \mathrm{~h}$ after injection of the tracer, Blood samples were collected at the time of scarification. The different organs were removed, washed, weighted and counted then compared to the standard solution of the labeled valsartan. The average percent values of the administrated injected dose per organ (ID/ organ) were calculated. Blood, bone, and muscles were assumed to be $7 \%, 10 \%$, and $40 \%$ of the total body weight, respectively [12].

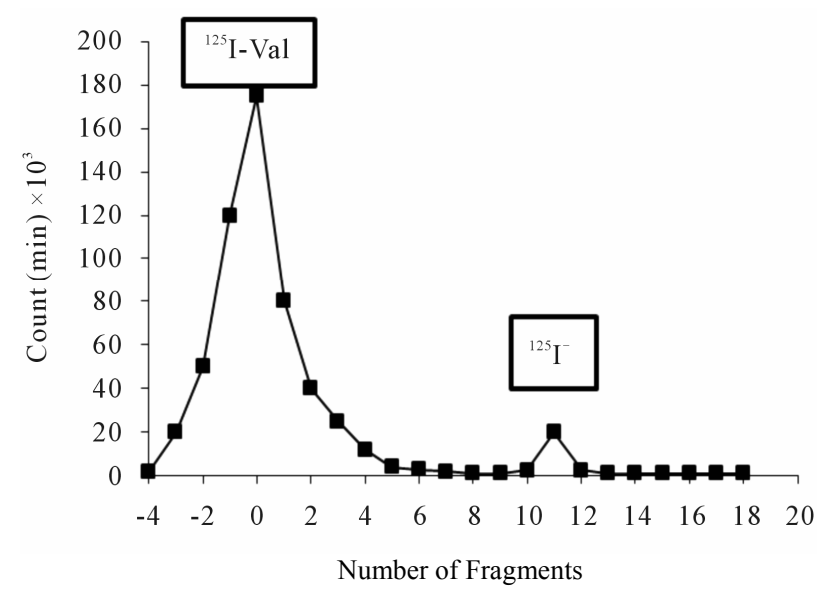

Figure 2. Electrophoresis pattern of ${ }^{125} \mathrm{I}-\mathrm{Val}$.

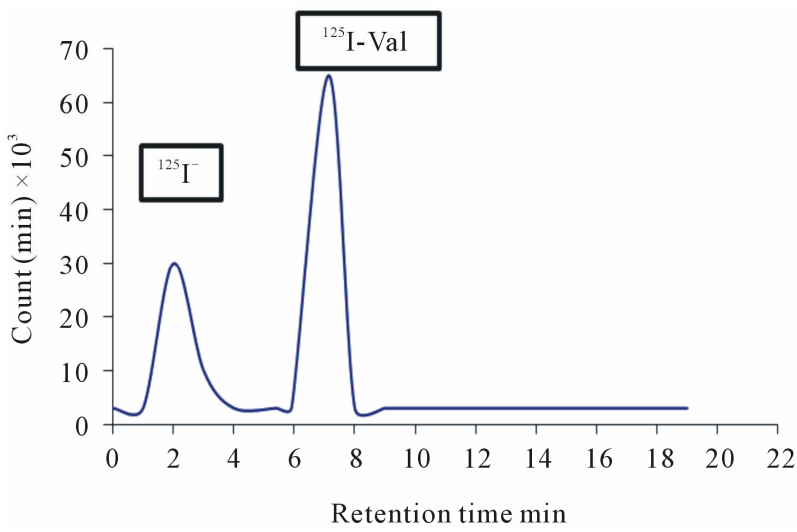

Figure 3. The HPLC separation of the labeled ${ }^{125} \mathrm{I}-\mathrm{Val}$ using 50 $\mu \mathrm{g}$ valsartan $(0.2 \mathrm{mM})$ and $25 \mu \mathrm{g}$ Iodogen $(0.15 \mathrm{mM})$ in room temperature within $30 \mathrm{~min}$. 


\section{RESULTS AND DISCUSSION}

\subsection{Effect of Valsartan Amount}

The influence of different valsartan amounts on the percentage of RCY of ${ }^{125} \mathrm{I}-\mathrm{Val}$ using $50 \mu \mathrm{g}$ CAT $(0.439$ $\mathrm{mM}$ ) as oxidizing agent at room temperature within 30 min was investigated in Figure 4. The data indicated that valsartan amount has no significant effect on the RCY of ${ }^{125} \mathrm{I}$-Val. Maximum RCY of ${ }^{125} \mathrm{I}-\mathrm{Val}$ (91.9) was achieved with valsartan amount equal to $50 \mu \mathrm{g}(0.2 \mathrm{mM})$. The RCY was not affected by increasing the amount of valsartan higher than $(50 \mu \mathrm{g})(0.2 \mathrm{mM})$. This may be attributed to the fact that the yield reaches the saturation value because the entire generated iodonium ions in the reaction were captured at that concentration of valsartan [10].

\subsection{Effect of Different Oxidizing Agents Amount}

To achieve an electrophilic substitution reaction, a suitable oxidizing agent, which required to give the maximum RCY was selected by using different oxidizing agents such as chloramine-T (CAT), the sodium salt of $n-$ chloro-4-toluenesulfonamide, Iodogen (1,3,4,6-tetrachloro$3 \alpha, 6 \alpha$-diphenylglycouril) and N-bromosuccinamide.

The influence of different CAT amounts on the percentage of RCY of ${ }^{125} \mathrm{I}-\mathrm{Val}$ using $50 \mu \mathrm{g}$ valsartan $(0.2$ $\mathrm{mM}$ ) at room temperature within 30 min was investigated in Figure 4. Maximum RCY of ${ }^{125} \mathrm{I}-\mathrm{Val}(91.9 \%)$ was achieved with CAT amount equal to $50 \mu \mathrm{g}(0.439$ $\mathrm{mM})$ The RCY was decreased by increasing the amount of CAT. This is due to the fact that the high concentration of CAT causes a number of undesirable oxidative side reactions including chlorination [13] and polymerization of substrate [14].

The RCY of ${ }^{125} \mathrm{I}-\mathrm{Val}$ increased up to $91.9 \%$ using 25 $\mu \mathrm{g}$ Iodogen $(0.15 \mathrm{mM})$, and this may due to negligible of the side reactions [9], and by increasing iodogen amount up to $300 \mu \mathrm{g}(0.62 \mathrm{mM})$, the RCY decreases down to $27 \%$. This attributed to precipitation of iodogen on the wall of the reaction vial with large amounts and the reaction total volume is small.

The RCY of ${ }^{125} \mathrm{I}-\mathrm{Val}$ decreases down to be $55 \%$ when $\mathrm{N}$-bromosuccinamide used as oxidizing agent and this may due to the side reactions (Figure 5).

\subsection{Effect of $\mathrm{pH}$ of the Reaction Mixture}

Figure 6 shows the variation of the RCY of ${ }^{125} \mathrm{I}-\mathrm{Val}$ as a function of $\mathrm{pH}$ of the reaction medium in presence of iodogen as oxidizing agent. The data clearly showed that a high $\mathrm{RCY}$ was obtained at $\mathrm{pH} 7$. When the $\mathrm{pH}$ of the reaction medium was shifted towards the acidic region, the yield decreased to $48.5 \%$ at $\mathrm{pH} 2$, this may be attrib-

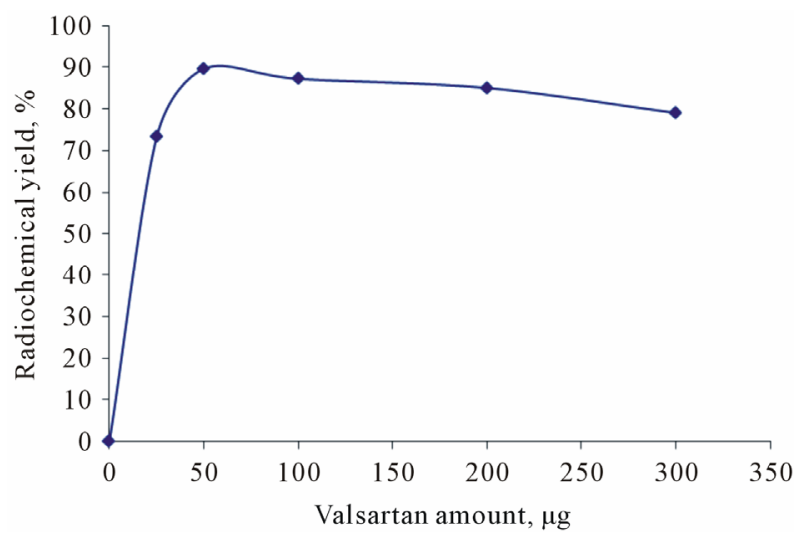

Figure 4. Effect of valsartan amount on the radiochemical yield using $50 \mu \mathrm{g} \mathrm{CAT}$ at room temperature within $30 \mathrm{~min}$.

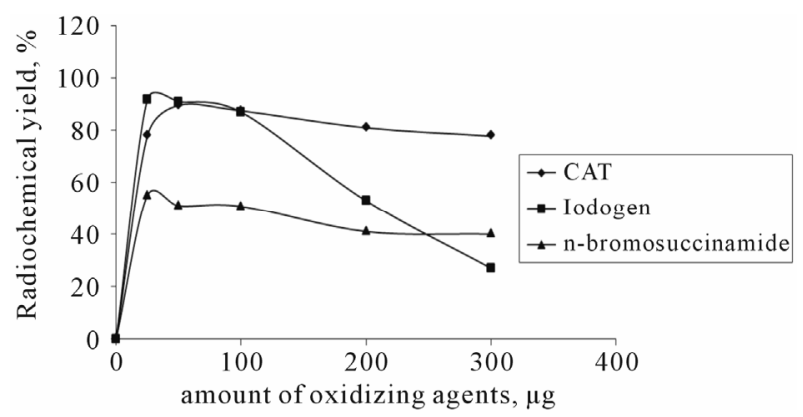

Figure 5. The effect of different oxidizing agents on the radiochemical yield using $50 \mu \mathrm{g}$ valsartan $(0.2 \mathrm{mM})$ in room temperature within $30 \mathrm{~min}$.

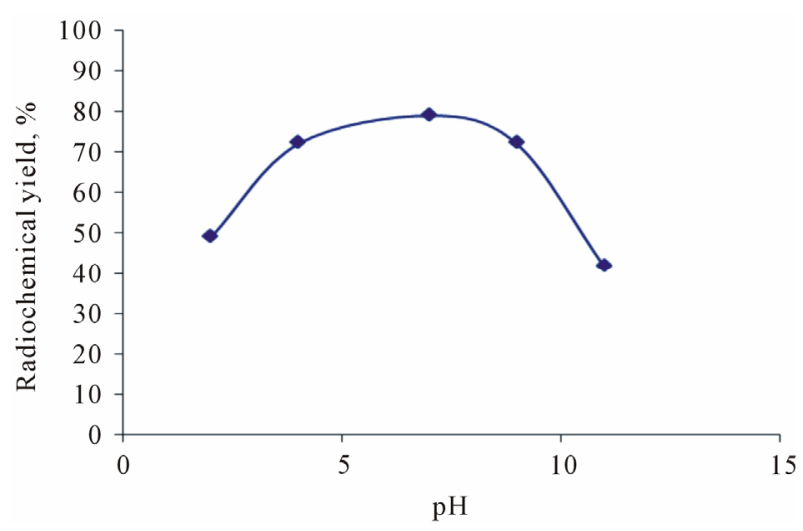

Figure 6. Effect of different $\mathrm{pH}$ on the radiochemical yield using $50 \mu \mathrm{g}$ valsartan $(0.2 \mathrm{mM})$ and $25 \mu \mathrm{g}$ iodogen $(0.15 \mathrm{mM})$ in room temperature within $30 \mathrm{~min}$.

uted to predominance of $\mathrm{ICl}$ species, which have low oxidation potential less than $\mathrm{HOCl}$ species [15]. In case of alkaline region, the yield of ${ }^{125} \mathrm{I}-\mathrm{Val}$ is relatively poor, as a result of decreasing HOI, which is responsible for electrophilic substitution reaction.

\subsection{Effect of the Reaction Temperature}

The reaction temperature plays an important role in 
the electrophilic substitution reactions. The leaving hydronium ion requires energy to break $\mathrm{C}-\mathrm{H}$ bond and to initiate the introducing of the radioactive iodoniom ion into the ring [13]. Figure 7 shows that the radiochemical yield of ${ }^{125} \mathrm{I}-\mathrm{Val}$ was high at room temperature reached to $91.9 \%$ and still stable up to $80^{\circ} \mathrm{C}$ and when the temperature raised up to $100^{\circ} \mathrm{C}$ the RCY decreases to $60.9 \%$ and this may attributed to thermal decomposition of the labeled compound.

\subsection{Effect of Reaction Time}

The radiochemical yield of ${ }^{125} \mathrm{I}$-Val was determined at different time intervals using $50 \mu \mathrm{g}$ valsartan $(2.3 \mathrm{mM})$ and $25 \mu \mathrm{g}$ iodogen $(0.15 \mathrm{mM})$ at room temperature, the highest RCY of $91.9 \%$ was obtained after $30 \mathrm{~min}$ as illustrated in Figure 8.

\subsection{Effect of Reaction Solvents}

The reaction between valsartan $50 \mu \mathrm{g}(2.3 \mathrm{mM})$ and $\mathrm{Na}^{125} \mathrm{I}(3.7 \mathrm{MBq})$ in the presence of Iodogen $25 \mu \mathrm{g}(0.15$ $\mathrm{mM})$ as oxidizing agent was examined in different organic solvents such as methanol, acetone, DMSO, DMF, chloroform and ethanol as shown in Table 1. The results indicated that the most suitable solvent was ethanol this may be due to valsartan completely soluble in ethanol. In spite of the advantageous characteristics of the dipolar aprotic solvent DMSO, DMF which include a high boiling point, ability to solvate a broad variety of solutes and to be useful in radioiodination reactions the labeling using DMSO as a solvent gave poor radiochemical yield of ${ }^{125} \mathrm{I}-\mathrm{Val}$.

\subsection{In-Vitro Stability}

The stability of ${ }^{125} \mathrm{I}$-Val was studied in order to determine the suitable time for imaging to avoid the formation of the undesired radioactive products that result from the radiolysis of the labeled compound. These undesired radioactive products may be toxic or accumulated in undesired organ. Table 2 shows that the stability of ${ }^{125} \mathrm{I}-\mathrm{Val}$ was decreased during $24 \mathrm{~h}$.

\subsection{Biodistribution}

Biodistribution in mice was studied to elucidate the biological pathway of the tracer. Table 3 shows the data collected from the injection of $200 \mu \mathrm{l}(3.5 \mathrm{MBq})$ of ${ }^{125} \mathrm{I}-$ Val intravenously (i.v.) in the tail vein of normal mice which were sacrificed at $0.5,1$ and $3 \mathrm{~h}$ post injection.

Data in Table 3 show that the blood activity was $15.4 \%$ at $0.5 \mathrm{~h}$ and remain nearly stable (11.3\%) up to 1 $\mathrm{h}$, then decrease to $6.7 \%$ at $3 \mathrm{~h}$ due to the binding of valsartan with plasma protein. Accumulations of ${ }^{125} \mathrm{I}-\mathrm{Val}$ in the heart with high activity reach to $10.7 \%$ after $0.5 \mathrm{~h}$.

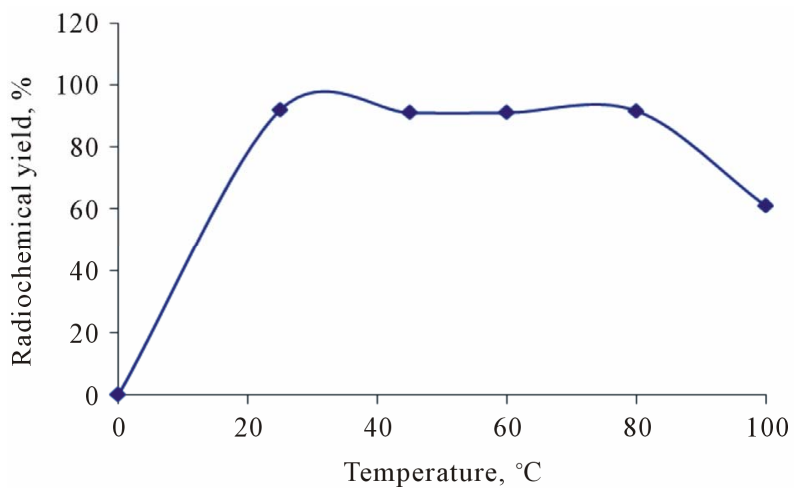

Figure 7. Effect of the reaction temperature on the radiochemical yield using $50 \mu \mathrm{g}$ valsartan $(0.2 \mathrm{mM})$ and $25 \mu \mathrm{g}$ iodogen $(0.15 \mathrm{mM})$ in room temperature within $30 \mathrm{~min}$.

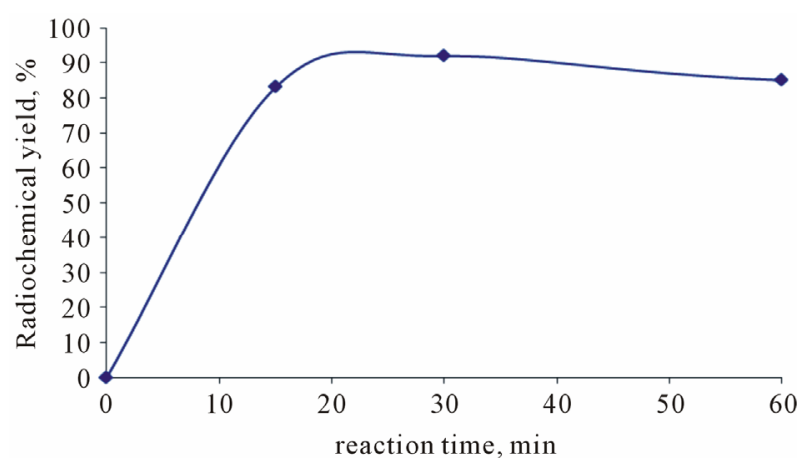

Figure 8. Effect of the reaction time on the radiochemical yield using $50 \mu \mathrm{g}$ valsartan $(0.2 \mathrm{mM})$ and $25 \mu \mathrm{g}$ iodogen $(0.15 \mathrm{mM})$ in room temperature at $\mathrm{X}$ min.

Table 1. Effect of different organic solvents on the radiochemical yield using $50 \mu \mathrm{g}$ valsartan $(0.2 \mathrm{mM})$ and $25 \mu \mathrm{g}$ iodogen $(0.15 \mathrm{mM})$ at room temperature within $30 \mathrm{~min}$.

\begin{tabular}{cc}
\hline Solvent & RCY, \% \\
\hline Methanol & $75 \% \pm 1.5$ \\
Acetone & $85 \% \pm 0.8$ \\
DMSO & $58 \% \pm 0.9$ \\
DMF & $63 \% \pm 1.3$ \\
Chloroform & $53 \% \pm 1$ \\
Ethanol & $92 \% \pm 0.7$ \\
\hline
\end{tabular}

Table 2. The in vitro stability of the radiochemical yield using $50 \mu \mathrm{g}$ valsartan $(0.2 \mathrm{mM})$ and $25 \mu \mathrm{g}$ iodogen $(0.15 \mathrm{mM})$ in room temperature within $30 \mathrm{~min}$.

\begin{tabular}{cc}
\hline Time, $\mathrm{h}$ & Radiochemical yield, $\%$ \\
\hline 1 & $85 \pm 1.3$ \\
2 & $80 \pm 1.4$ \\
4 & $77 \pm 1.5$ \\
8 & $75.6 \pm 1.2$ \\
12 & $74 \pm 1.3$ \\
24 & $70.1 \pm 2$ \\
\hline
\end{tabular}


Table 3. The Biological distribution of ${ }^{125} \mathrm{I}-\mathrm{Val}$ in mice.

\begin{tabular}{cccc}
\hline \multirow{2}{*}{$\begin{array}{c}\text { Organs \& body } \\
\text { fluids }\end{array}$} & \multicolumn{3}{c}{$\begin{array}{c}\text { Detected dose/organ percent at different time } \\
\text { intervals post injection (min) }\end{array}$} \\
\cline { 2 - 4 } & $30 \mathrm{~min}$ & $60 \mathrm{~min}$ & $180 \mathrm{~min}$ \\
\hline Blood & $15.4 \pm 1.2$ & $11.3 \pm 1$ & $6.7 \pm 0.9$ \\
Bone & $2.2 \pm 0.4$ & $3.2 \pm 0.3$ & $2.5 \pm 0.4$ \\
Muscle & $5.8 \pm 0.8$ & $4.5 \pm 0.6$ & $3.5 \pm 0.5$ \\
Heart & $10.7 \pm 1.1$ & $16.9 \pm 0.9$ & $12.5 \pm 0.7$ \\
Lung & $3.5 \pm 0.1$ & $2.4 \pm 0.04$ & $1.1 \pm 0.1$ \\
Stomach & $9.3 \pm 0.7$ & $10.6 \pm 0.8$ & $6.3 \pm 0.5$ \\
Intestine & $6.6 \pm 0.5$ & $9.8 \pm 0.8$ & $5.4 \pm 0.7$ \\
Liver & $8.8 \pm 0.3$ & $7.9 \pm 0.3$ & $9.7 \pm 0.3$ \\
Kidneys & $11.3 \pm 0.4$ & $13.2 \pm 0.3$ & $11.8 \pm 0.1$ \\
Urine & $14.6 \pm 0.5$ & $16.8 \pm 1.1$ & $31 \pm 1.6$ \\
Spleen & $1.5 \pm 0.01$ & $1.3 \pm 0.02$ & $1.1 \pm 0.01$ \\
Thyroid & $0.06 \pm 0.02$ & $0.09 \pm 0.01$ & $0.18 \pm 0.07$ \\
\hline
\end{tabular}

This high activity ratio for blood and heart indicate the possibility of ${ }^{125} \mathrm{I}-\mathrm{V}$ al to be used in imaging of cardiovasculat disorders.

The high activity in stomach is due to that valsartan is highly absorbed by stomach without regard of food intake. The tracer was extracted through hepatobilary and urinary pathway. This was confirmed as urine activity reached to $31 \%$ after $3 \mathrm{~h}$ post injection, and the intestines activity reached to $5.4 \%$ after $3 \mathrm{~h}$ post injection. Table 3 includes the biodistribution pattern of ${ }^{125} \mathrm{I}-\mathrm{Val}$. The thyroid uptake was mostly ranged from $0.06 \%$ to $0.1 \%$ within $3 \mathrm{~h}$ indicating that ${ }^{125} \mathrm{I}-\mathrm{V}$ al free form radioiodide and it is stable in-vivo.

\section{CONCLUSION}

To achive a high radiochemical yield of ${ }^{125} \mathrm{I}-\mathrm{Val} 98.8 \%$, $50 \mu \mathrm{g}$ valsartan $(0.2 \mathrm{mM})$ and $25 \mu \mathrm{g}$ Iodogen $(0.15 \mathrm{mM})$ was used at room temperature within $30 \mathrm{~min}$. Biodistribution indicate that ${ }^{125} \mathrm{I}-\mathrm{Val}$ can be easily and safely used in Cardiovascular disorder imaging.

\section{REFERENCES}

[1] Hiari, N. and Rudd, J.H.F. (2011) FDG-PET imaging and cardiovascular inflammation. Current Cardiology Reports, 13, 43-48.

[2] Rogers, I.S. and Tawakol, A. (2011) Imaging of coronary inflammation with FDG-PET: Feasibility and clinical hurdles. Current Cardiology Reports.

[3] Matsunari, I., Taki, J., Nakajima, K., Tonami, N. and Hisada, K. (2003) Myocardial viability assessment using nuclear imaging. Annals of Nuclear Medicine, 17, 169179.

[4] Barakat, K., Clark, R. and Davi, M. (2004) Valsartan hypertension and cardiovascular disease book. CSF Medical Communications, Witney.

[5] Aronson, J.K. (2009) Meyler's side effects of cardiovascular drugs book. Elsevier Science, Amsterdam.

[6] Holwerda, N.J., Fogari, R., Angeli, P., Porcellati, C., Hereng, C. and Oddou-Stock, P. (1996) Valsartan, a new angiotensin II antagonist for the treatment of essential hypertension: Efficacy and safety compared with placebo and enalapril. Journal of Hypertension, 14, 1147-1151. doi:10.1097/00004872-199609000-00016

[7] Black, H.R., Graff, A., Shute, D., Stoltz, R., Ruff, D. and Levine, J. (1997) Valsartan, a new angiotensin II antagonist for the treatment of essential hypertension: Efficacy, tolerability and safety compared to an angiotensin-converting enzyme inhibitor, lisinopril. Journal of Human Hypertension, 11, 483-489. doi:10.1038/sj.jhh.1000482

[8] Waldmeier, F., Flesch, G., Müller, P., Winkler, T., Kriemler, H.P., Bühlmayer, P. and De Gasparo, M. (1997) Pharmacokinetics, disposition and biotransformation of $\left[{ }^{14} \mathrm{C}\right]-$ radiolabeled valsartan in healthy male volunteers after a single oral dose. Xenobiotica, 27, 59-71.

[9] Hermanson, G.T. (2008) Bioconjugated techniques book. 2nd Edition, Elsevier, Amsterdam.

[10] El-Azony, K.M., El-Mohty, A.A., Killa, H.M., Seddik, U. and Khater, S.I. (2008) An investigation of the ${ }^{125}$ I-radioiodination of colchicine for medical purposes. Journal of Labelled Compounds and Radiopharmaceuticals, 52, 1. doi:10.1002/jlcr. 1556

[11] Attallah, K.M. (2002) Pharmaceutical formulation, radiochemical and biological evaluation of some iodine-125 labeled cytotoxic compounds as possible radiotherapeutic agents. M.Sc. Thesis, Zagazig University.

[12] Rhodes, B.A. (1974) Technetium-99m labeled polypeptides for imaging. Seminars in Nuclear Medicine, 4, 281. doi:10.1016/S0001-2998(74)80015-2

[13] Knust, E.J., Dutschka, K. and Machulla, H.J. (1990) Radiopharmaceutical preparation of $3-{ }^{123} \mathrm{I}-\alpha$-methyltyrosine for nuclearmedical applications. Journal of Radioanalytical and Nuclear Chemistry, 10, 144

[14] EL-Ghany, E.A., Moustafa, D. and Shokry, M.S. (2009) Iodine-125-Tamoxifan ( ${ }^{125}$ ITX); radioligand for visualization of estrogen receptors: Preparation and tissue distribution. Arab Journal of Nuclear Sciences and Applications, 42, 80 .

[15] El-Azony, K.M. (2010) Preparation of 125I-celecoxib with high purity as a possible tumor agent. Journal of Radioanalytical and Nuclear Chemistry, 285, 315-320. 